\title{
Interferon for Chinese patients with chronic hepatitis B e antigen- positive diseases-the controversy arises again?
}

\author{
George K. K. Lau
}

Received: 21 April 2014/ Accepted: 16 June 2014/Published online: 9 July 2014

(C) Asian Pacific Association for the Study of the Liver 2014

In 2014, seven drugs were registered for the treatment of chronic hepatitis B (CHB) infection. Two were immunomodulatory agents, conventional interferon(IFN)- $\alpha$ and pegylated IFN- $\alpha 2 \mathrm{a}$, and five were direct antiviral nucleos(t)ide analogs (NUCs), lamivudine, adefovir dipivoxil, telbivudine, entecavir and tenofovir disoproxil fumarate. Due to the high resistance barrier of entecavir and tenofovir as compared to the other NUCs, only these two drugs are now in practical use in most parts of the world [1].

For chronic hepatitis $\mathrm{B}$ e antigen ( $\mathrm{HBe} \mathrm{Ag}$ )-positive patients, $\mathrm{HBeAg}$ seroconversion, defined as the loss of $\mathrm{HBeAg}$ with the appearance of anti-HBe, is often associated with clinical remission and a transition to inactive liver disease. Accompanying $\mathrm{HBeAg}$ seroconversion, there is a reduction in liver fibrosis and a lower incidence of cirrhosis and hepatocellular carcinoma. $\mathrm{HBeAg}$ seroconversion, whether spontaneous or treatment induced, is also associated with a higher probability of hepatitis B surface antigen ( $\mathrm{HBsAg}$ ) loss and seroconversion, which is considered to be a more permanent clinical remission of liver disease. Thus, the achievement as well as maintenance of $\mathrm{HBeAg}$ seroconversion, in association with low serum hepatitis B virus (HBV) DNA levels $(<3-4 \log \mathrm{IU} / \mathrm{ml})$, is an important goal in the management of patients with HBeAg-positive CHB [2]. Based on evidence demonstrating $\mathrm{HBeAg}$ seroconversion is an important hallmark event of a durable clinical remission of liver disease, most

G. K. K. Lau ( $\square)$

Humanity and Health GI and Liver Centre, Hong Kong, Hong

Kong SAR

e-mail: gkklau@netvigator.com

G. K. K. Lau

The Institute of Translational Hepatology, Beijing 302 Hospital, Beijing, China hepatology society treatment guidelines have adopted $\mathrm{HBe} A g$ seroconversion with sustained suppression of HBV DNA as an end point for treatment in patients with $\mathrm{HBeAg}$ positive CHB who do not have cirrhosis or decompensated liver disease [1]. Previously, the conflicting data related to the importance of $\mathrm{HBeAg}$ seroconversion were largely related to the existence of a group of $\mathrm{HBeAg}$ seroconverters with a high HBV DNA viral load. In fact, this merely represented a transition from chronic $\mathrm{HBeAg}$ positive disease to chronic $\mathrm{HBeAg}$-negative disease, with little impact on the natural history of CHB. This important point was emphasized by a recent study in Taiwan, which included 2,946 chronic CHB Chinese patients. It was shown that high serum HBV DNA levels at the seroclearance of $\mathrm{HBeAg}$ could explain the nonsignificant association between $\mathrm{HBeAg}$ seroclearance and HCC risk [3].

Among the various forms of treatment, 1-year treatment with pegylated IFN- $\alpha 2$ a yielded the highest rate of $\mathrm{HBeAg}$ seroconversion (around $40 \%$ ); among them, one-tenth further benefited from HBsAg seroconversion. On the other hand, treatment with NUCs achieved a much lower rate of $\mathrm{HBeAg}$ seroconversion; hence, more prolonged therapy is required when one has started treating CHB patients with NUCs. Hence, one of the key questions is related to the durability of $\mathrm{HBeAg}$ seroconversion with the various forms of therapy. This will affect the physician's decision when choosing a therapy for our chronic $\mathrm{HBeAg}$-positive patients between nucleos(t)ide analogs (NUCs) or pegylated IFN. Clinically, this has always led to a painful choice between either life-long medication with NUCs with a high genetic barrier (entecavir or tenofovir disoproxil fumarate) or lasting remission with a relatively short duration but sometimes side effect-prone therapy with 48 weeks of pegylated IFN. Previously, two large-scale clinical studies in Chinese subjects demonstrated that treatment with 
pegylated IFN could lead to a significantly higher rate of $\mathrm{HBeAg}$ serconversion (around 4 out of 10) as compared to those treated with NUCs $[4,5]$. Specifically, the registration trial of pegylated interferon-alpha $2 \mathrm{a}$ included mainly Chinese patients with genotype B and C [5]. This strongly argued against the lack of efficacy of IFN-based therapy in Chinese patients with chronic HBV infection. In keeping with this, a long-term follow-up study (median 6.8 years, range up to 17 years) of a large cohort of Chinese chronic HBeAg-positive patients demonstrated by multivariate analysis that IFN therapy, $\mathrm{HBeAg}$ seroconversion and genotype $\mathrm{B} \mathrm{HBV}$ infection are independent factors predicting better long-term outcomes and IFN therapy reduces the cirrhosis and HCC development [6].

In this issue, Chen et al. reinitiated an adverse opinion on the use of IFN-based therapy in chronic HBeAg-positive Chinese patients [7]. They examined whether $\mathrm{HBeAg}$ seroconversion related to IFN-based therapy in chronic $\mathrm{HBeAg}$-positive patients is durable and compared the risk of hepatitis $\mathrm{B}$ virus (HBV) reactivation and $\mathrm{HBeAg}$ seroreversion to those of spontaneous $\mathrm{HBeAg}$ seroconversion (control group). This is an important question as it has been suggested that the lack of response of some of the chronic HBeAg-positive Chinese patients to IFN-based therapy is related to the high rate of $\mathrm{HBeAg}$ seroreversion in these patients. However, not until recently was the durability of $\mathrm{HBeAg}$ seroconversion in Chinese patients treated with pegylated IFN therapy addressed. In a report by the Hong Kong group, $85 \mathrm{HBeAg}$-positive patients who received pegylated IFN alfa-2b based therapy were prospectively followed for 5 years. Among end-of-treatment virologic responders, 82 and $57 \%$ had sustained HBeAg seroconversion and virologic response at 5 years. Hence, it was concluded that treatment with pegylated IFN can lead to a highly durable virologic response in $\mathrm{HBeAg}$-positive chronic HBV patients [8]. This is in contrast to the data reported by Chen et al. in this issue [7]. In Chen's study, 331 non-cirrhotic chronic $\mathrm{HBeAg}$-positive patients followed up at a single center at the Kaohsiung Chang Gung Memorial Hospital, Taiwan, were examined. Among them, 80 patients had previously been treated with IFN-based therapy and 251 had spontaneous HBeAg seroconversion. The author concluded that IFN-induced HBeAg seroconverters were associated with higher risks of HBV reactivation and $\mathrm{HBeAg}$ seroreversion than those with spontaneous $\mathrm{HBeAg}$ seroconversion, especially in patients older than 30 years of age at HBeAg seroconversion. At year 5, the cumulative rates of $\mathrm{HBV}$ reactivation and HBeAg seroreversion were 51.2 and $21.5 \%$ in those treated with IFN-based therapy. In Chen et al.'s study, further follow-up on those who did not initially respond to IFN-based therapy was not included. This is one of the major drawbacks to the study and has weakened their conclusions that IFN or pegylated IFN did not have a lasting effect after stopping the therapy. In keeping with this, also no patients benefited from the loss of $\mathrm{HBsAg}$, which is the ultimate goal of anti-HBV therapy. In all other large-scale studies, there was a significant albiet low rate of HBsAg loss for chronic $\mathrm{HBeAg}$-positive patients treated with IFN-based therapy (especially pegylated IFN). Indeed, in the Hong Kong study reported by Wong et al., which also involved Chinese patients treated with IFN-based therapy, the $\mathrm{HBeAg}$ seroconversion rate was found to continue to increase on long-term follow-up and almost double by 5 years. It was found that the rate of $\mathrm{HBeAg}$ seroconversion rose progressively from $37 \%$ at the end of treatment to $60 \%$ at 5 years [8]. Another interesting and relevant finding in the Chen et al. study is related to the observation that, for patients who experienced $\mathrm{HBeAg}$ seroconversion at $\leq 30$ years of age, IFN-induced $\mathrm{HBeAg}$ seroconversion was not an independent factor for predicting $\mathrm{HBV}$ reactivation and $\mathrm{HBeAg}$ seroreversion. This supports the general belief that one should try IFN-based therapy in young and motivated chronic HBeAg-positive patients.

Overall, the study by Chen et al. suffered from a few limitations, which prevent reaching firm conclusions. First, this was a retrospective study treating a heterogeneous group of subjects-some with conventional interferon (probably of variable duration) and some with pegylated interferon. Second, the study spanned a long time period, with potential variability in the standard of care and loss of follow-up records. Third, the number of subjects included was relatively small, which might have a negative impact on the statistical interpretation of the data generated. Fourth, the control group might be skewed as effective treatment was already available in 1998, and those who remained untreated might represent a different group of $\mathrm{CHB}$ patients treated with IFN-based therapy. It would be more enlightening if further study could include all the chronic $\mathrm{HBeAg}$-positive patients treated with all different forms of therapy (IFN-based versus NUCs) at the same period of time. Indeed, with the report by Chen et al., more questions have arisen than answers, and better designed studies are required to examine the durability of $\mathrm{HBeAg}$ seroconversion in Chinese patients treated with IFN-based therapy.

From the clinical point of view, durable $\mathrm{HBeAg}$ seroconversion with a low serum HBV DNA viral load $(<4$ log $\mathrm{IU} / \mathrm{ml})$ is the essential intermediate step toward lasting remission [2]. Apart from the viral genotype and serum HBV DNA, the dynamic quantitative changes of the precore stop codon (PC) G1896A and basal core promoter (BCP) A1762T, G1764A mutants, characterized by polymerase chain reaction-pyrosequencing, have recently been suggested to be of importance [9, 10]. The evolution of PC 
mutation, but not that of $\mathrm{BCP}$ mutation, predicts serological clearance of $\mathrm{HBeAg}$ with low HBV DNA in chronic HBeAg-positive patients treated with interferon-based therapy. Further understanding of the underlying mechanisms that lead to such a durable $\mathrm{HBeAg}$ seroconversion and the factors that are related to $\mathrm{HBeAg}$ seroreversion and viral reactivation will help predict the prognosis of CHB patients as well as design better follow-up and antiviral therapy strategies.

\section{References}

1. Liaw YF, Kao JH, Piratvisuth T, et al. Asian-Pacific consensus statement on the management of chronic hepatitis B: a 2012 update. Hepatol Int 2012;6(3):531-561

2. Liaw YF, Lau GK, Kao JH, Gane E. Hepatitis B e antigen seroconversion: a critical event in chronic hepatitis B virus infection. Dig Dis Sci 2010;55(10):2727-2734

3. Liu J, Yang HI, Lee MH, et al. Spontaneous seroclearance of hepatitis B seromarkers and subsequent risk of hepatocellular carcinoma. Gut 2013;. doi:10.1136/gutjnl-2013-305785
4. Chan HL, Leung NW, Hui AY, et al. A randomized, controlled trial of combination therapy for chronic hepatitis B: comparing pegylated interferon-alpha2b and lamivudine with lamivudine alone. Ann Intern Med 2005;142(4):240-250

5. Lau GK, Piratvisuth T, Luo KX, et al. Peginterferon Alfa-2a, lamivudine, and the combination for $\mathrm{HBeAg}$-positive chronic hepatitis B. N Engl J Med 2005;352(26):2682-2695

6. Lin SM, Yu ML, Lee CM, et al. Interferon therapy in $\mathrm{HBeAg}$ positive chronic hepatitis reduces progression to cirrhosis and hepatocellular carcinoma. J Hepatol 2007;46(1):45-52

7. Chen $\mathrm{CH}, \mathrm{Lu} \mathrm{SN}$, Lee CM, et al. Patients with interferon-induced $\mathrm{HBeAg}$ seroconversion have a higher risk of HBV reactivation and $\mathrm{HBeAg}$ seroreversion. Hepatol Int (in press)

8. Wong VW, Wong GL, Yan KK, et al. Durability of peginterferon alfa-2b treatment at 5 years in patients with hepatitis B e antigenpositive chronic hepatitis B. Hepatology 2010;51(6):1945-1953

9. Kao JH. Role of viral factors in the natural course and therapy of chronic hepatitis B. Hepatol Int 2007;1:415-430

10. Yang HC, Chen CL, Shen YC, et al. Distinct evolution and predictive value of hepatitis $\mathrm{B}$ virus precore and basal core promoter mutations in interferon-induced hepatitis B e antigen seroconversion. Hepatology 2013;57(3):934-943 